\title{
Dark-field TEM study of the microstructural behavior in AZ31B/MWCNTs composites produced by the sandwich technique
}

Cesar Isaza $^{1}$, Yamile Cardona-Maya ${ }^{2}$, Juan Rudas ${ }^{1}$, C. Carreño-Gallardo ${ }^{3}$, José Herrera-Ramirez ${ }^{4}$ and Juan Meza ${ }^{5}$

${ }^{1}$ Institución Universitaria Pascual Bravo, Facultad de Ingeniería, Grupo GIIEN, A. A. 6564, campus Robledo, Medellín, Colombia., United States, ${ }^{2}$ Departamento de Ciencias Básicas, Universidad Católica Luis Amigó, Transversal 51A \#67B 90, Medellín, Colombia., Antioquia, Colombia, ${ }^{3}$ Centro de Investigación en Materiales Avanzados (CIMAV), Chihuahua, Chihuahua, Mexico, ${ }^{4}$ Centro de Investigación en Materiales Avanzados (CIMAV), Laboratorio Nacional de Nanotecnología, Miguel de Cervantes 120, 31136 Chihuahua, México, United States, ${ }^{5}$ Universidad Nacional de Colombia, Facultad de Minas, Departamento de Materiales y Minerales, Design of Advanced Composites (DADCOMP), Cl 75 No 79A 51, 050032, Medellín, Colombia, United States

Metal matrix composites have been constantly used in aeronautical, aerospace and industrial applications [1]. Similarly, some nanomaterials such as carbon nanotubes (CNTs), silicon carbide (SiC) and alumina (Al2O3) nanoparticles have been used as nanoreinforcements in metallic matrices, obtaining high mechanical properties and some functional properties such as sensors and actuators [2]. Isaza et al. [3, 4] developed a methodology for manufacturing aluminum or magnesium matrix reinforced with CNTs, called sandwich technique. In those works, it was found that with the addition of the nanoreinforcement into the metallic matrix, all its tensile mechanical properties (elastic modulus, yield strength and maximum strength) are increased. Contrary to what was expected and reported of various authors [5], the composites also exhibited an important plastic behavior. In order to understand this behavior, a transmission electronic microscope (TEM) JEOL 2010 was used in the areas near the interface between the reinforcement and the matrix. Dark-field TEM images consist on identifying in diffraction patterns some spots different to those coming from the central electron beam. With this selection, the electron beam passes across the sample in just one specific orientation, thus the contrast in the image is associated with either different crystalline planes or different phases.

Figure 1a shows scanning electron microscopy (SEM) images of the manufactured composites. The dark areas correspond to a greater concentration of nanoreinforcements, where the dark-field TEM analyzes were carried out to identify the microstructural changes produced by the manufacturing process. Figures $1 \mathrm{~b}$ and 2 show darkfield TEM images for the composites reinforced with 0.25 and $1.0 \mathrm{wt} . \%$ MWCNTs, respectively. From these images, several spots were analyzed, being easy to identify different grain orientation and size $(\sim 10-60 \mathrm{~nm}$ in equivalent diameter for both composites). With these images, it is corroborated that a recrystallization process took place during the composite manufacturing, which allows improving the mechanical properties by the HallPetch relationship; i.e., the MWCNTs are acting as nucleation sites, restringing the grain growth by the pinning effect [6] during the nucleation stage. The small grain sizes caused the remarkable improved yield strength. Thus, the load transfer mechanism and the Hall-Petch relationship dominate the increment in mechanical properties of the composites. The Hall-Petch equation relates the grain size to the yield strength, which is related with the deformation mechanisms like dislocations. Accordingly, small grain sizes can also allow sliding between grains, which is a mechanism that enhances the plasticity in the materials. 


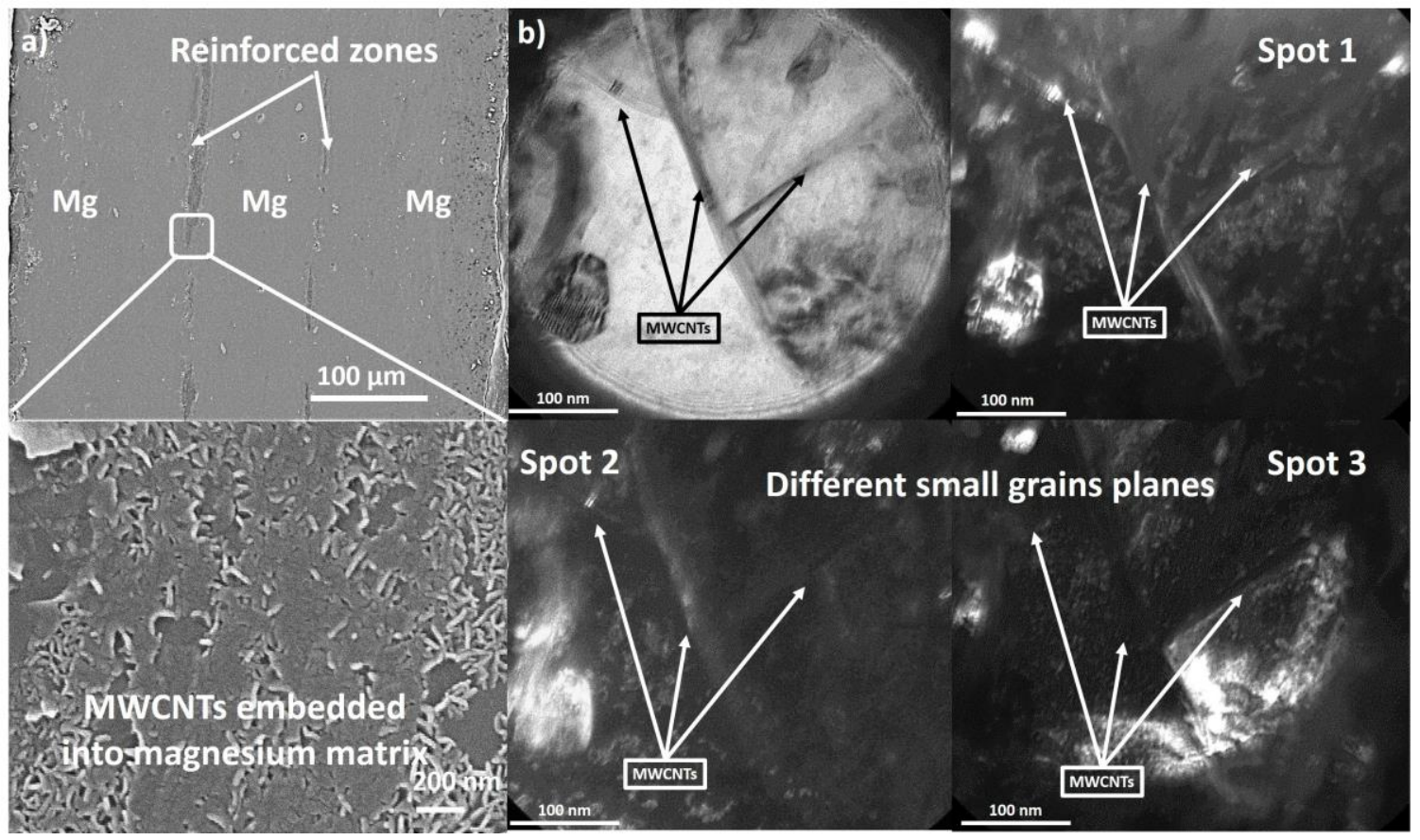

Figure 1. a) SEM images for magnesium reinforced with 1.0 wt.\% MWCNTs and b) Dark-field TEM images for magnesium reinforced with $0.25 \mathrm{wt}$ \% MWCNTs.

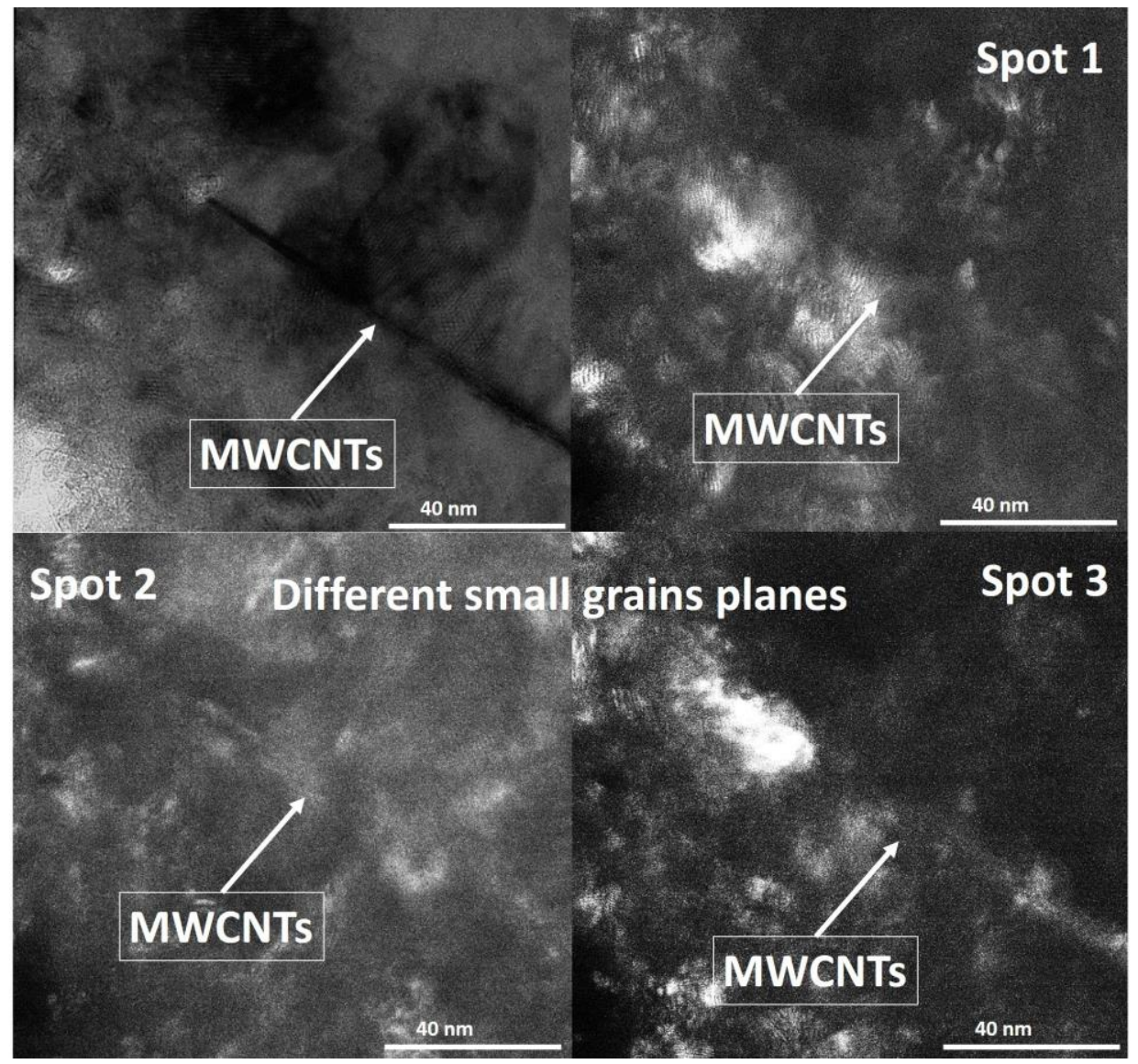

Figure 2. Dark-field TEM images for magnesium reinforced with $1.0 \mathrm{wt} . \%$ MWCNTs. 


\section{References}

[1] Chawla KK. Compos. Mater., Spring. N.Y.; 2012, p. 197-248.

[2] Li C, Thostenson ET, Chou T-W. Comps. Sci. and Tech., 2008, p. 1227-1249.

[3] Merino CAI, Ledezma JE, Meza JM, Herrera Ramirez JM. Elsevier, J. of All. and Compo., 2016, p 257-263

[4] Ramirez J, Bustamante R, Merino C. Spring., 2020, p. 1-232.

[5] Salama E, Abbas A, and AE-CPAAS, Compos. P. A: Appl. Sci. and Manuf., 2017, p. 84-93.

[6] Xu JQ, Chen LY, Choi H, Li XC. J. of Phys.: Cond. Matt. 2012, p. 1-10 